\title{
Geochemical constraints on mantle plumes
}

\author{
CATHERINe ChAUVEL $^{1}$ \\ ${ }^{1}$ IPGP, CNRS, Paris, France; chauvel@ipgp.fr
}

Ever since their discovery, mantle plumes have fascinated the scientific community. This is particularly the case for geochemists because mantle plumes bring to the surface volcanic rocks whose composition differs significantly from that of mid-ocean ridge volcanics (MORB). This was first discovered in the late 1970's [1,2] and the isotopic differences interpreted as due to mixing processes between a primitive mantle and a more depleted mantle. Things have quickly changed. For example, the constant and non-primitive $\mathrm{Ce} / \mathrm{Pb}$ and $\mathrm{Nb} / \mathrm{U}$ ratios of MORB and ocean island basalts (OIB) demonstrated that the two volcanic types sample similar sources and these sources differ significantly from bulk silicate Earth [3]. Radiogenic isotopes measured on a large number of ocean islands also helped defining the diversity of plume sources and demonstrated the potentially crucial role of recycled oceanic and continental material in the mantle.

More recent studies have drastically improved our understanding of the origin of plume volcanism. The advent of high-precision $\mathrm{Pb}$ isotopic measurements revealed that mantle plumes can have bilateral isotopic zoning lasting for millions of years [4] and its origin could potentially be linked to differential sampling of LLSVPs and ordinary lower mantle [5]. The recent development of extremely precise isotopic measurements allows now the detection of minute deviations in ratios that used to be seen as constant. Small but potentially significant ${ }^{142} \mathrm{Nd}$ anomalies detected in some OIB suggest that their source contains material untouched since early Earth [6]. Similarly, the presence of ${ }^{182} \mathrm{~W}$ anomalies associated to the presence of primitive helium suggests a very ancient, primitive and deep origin to some OIB sources [7]. In contrast, the presence of mass-independent fractionation of sulfur isotopes in some OIB demonstrates the presence in their source of material present at the surface of the Earth more than $2.45 \mathrm{Ga}$ ago $[8,9]$. All these new observations need to be combined in a coherent geochemical model for the origin of ocean island basalts, model that can then be confronted to the new high-resolution tomographic models that trace the deep roots of active mantle plumes.

[1] Richard et al. EPSL 1976, [2] O'Nions et al. EPSL 1977, [3.]

Hofmann et al. EPSL 1986, [4] Abouchami et al. Nature 2005, [5]

Weis et al. Nature Geosci 2011, [6] Peters et al. Nature 2018, [7]

Mundl et al. Science 2017, [8] Cabral et al. Nature 2013, [9]

Delavault et al. PNAS 2016. 